\title{
War er ein Tier?... Considerações sobre o bestiário de Kafka
}

Manuela Ribeiro Barbosa Doutoranda em Literatura Comparada (Pós-Graduação em Estudos Literários / UFMG)

\begin{abstract}
RESUMO
Apresenta-se o resultado de algumas leituras sobre a presença dos animais na obra de Kafka, sugerindo-se que as numerosas aparições de seres vivos não humanos em sua produção não se reúnem sob uma única rubrica, mas são dotadas da mobilidade e instabilidade característica dos viventes.
\end{abstract}

\section{PALAVRAS-CHAVE}

Kafka, animais, teoria, poesia

\footnotetext{
"Uma gaiola foi caçar um pássaro.”"

"E hoje, são corvos as cotovias!”²
}

Só pude perceber o alcance da “desatinada variedade do reino animal” de que fala Jorge Luis Borges e Margarita Guerrero no "Prólogo” do Manual de zoología fantástica depois de visitar um oceanário; a descoberta de peixes que podem optar pelo gênero sexual conforme a necessidade do cardume me fez ceder, ainda que tarde, à lógica expressa na assertiva, a qual - para castigo da teimosia pretensiosa - já previa como óbvio o equívoco do senso comum: a zoologia dos sonhos humanos é mais pobre que a zoologia de Deus. ${ }^{3}$ Efetivamente, não serão quase inacreditáveis as habilidades do mimo ou mockingbird, ave canora que pode reproduzir uma incrível gama de sons (inclusive mecânicos)? E do cavalomarinho, cujo macho, grávido, carrega os filhotes durante a gestação? Que dizer, então, dos

\footnotetext{
1 “Ein Käfig ging ein Vogel fangen”. (KAFKA. Das Werk, p. 657.) Esse aforismo aparece sob a variante "Ein Käfig ging ein Vogel suchen", com o verbo "procurar", mas optamos por priorizar a sonoridade, que nos parece mais expressiva na repetição do /f/ e do /g/. (Quando não houver menção contrária, as traduções são nossas.)

${ }^{2}$ TSVETÁIEVA. Ainda ontem, em meus olhos o teu olhar, p. 81.

${ }^{3}$ BORGES; GUERRERO. Manual de zoología fantástica, p. 2.
} 
dinossauros, cujos meros vestígios já nos aterrorizam? Mas a ficção tampouco se deixa vencer facilmente; talvez porque nela igualmente pulse a força da vida, não só daqueles “que habitam uma pele humana”, 4 para ecoar um autor cuja exploração do universo animal é tão densa, ou que se vistam de um "pobre invólucro humano", 5 para retomar outro que é prata da casa. O fabulário de Mário de Carvalho, as coisas-animais de Felisberto Hernández, a autossuficiência da natureza em Emily Dickinson, a ironia cúmplice de Pirandello e a narrativa bíblica constituem um mesmo - e no entanto múltiplo e diverso - universo de apropriações dos animais nesse abrigo que se chama poesia. É contudo necessário, diante do desvario, escolher, avaliar, estudar. É isso que o bom humor de Mário Quintana sintetiza com certa maldade: “Cada vez que o poeta cria uma borboleta, o leitor exclama: 'Olha uma borboleta!' O crítico ajusta os nasóculos e, ante aquele pedaço esvoaçante de vida, murmura: - Ah! sim, um lepidóptero"... ${ }^{6}$ Porém é tempo de voltar a Kafka, que, afinal, é o pássaro misterioso de que nos vamos ora ocupar.

War er ein Tier, da ihm Musik so ergriff? A pergunta que Gregor Samsa se faz na Metamorfose (Die Verwandlung) também nos interpela quando examinamos o bicho Kafka, em cuja obra a presença dos animais foi assinalada desde os primórdios. ${ }^{7}$ Um levantamento superficial do bestiário kafkiano nos põe frente a gatos, cavalos, aranhas, raposas, papagaios, formigas, cachorros, camundongos, ratos, percevejos, lobos, pulgas, abutres, águias, leopardos, pardais, macacos, besouros, panteras, trutas, sapos, serpentes, chacais, ratos d’água, moscas, toupeiras, camelos, pombos, corvos, gralhas, leões (para não recordar

${ }^{4}$ DÖBLIN. Berlin Alexanderplatz, p. 10. O autor oferece um vastíssimo campo de estudo da animalidade como metáfora da existência humana, do sacrifício e da nossa cegueira diante da dor.

${ }^{5}$ RUBIÃO. O pirotécnico Zacarias, p. 14.

${ }^{6}$ QUINTANA. A borboleta, p. 92.

${ }^{7}$ Walter Benjamin, em 1934, e Max Brod (“Wie Gott dem Menschen nicht oder nur sehr lückenhaft verständlich werden kann (Hiob), so auch das Tier dem Menschen nicht oder nur lückenhaft. So auch der Mensch dem Tier nicht, wie Kafka in seiner melancholischen Travestie des Atheismus, den 'Forschungen eines Hundes' es gestaltet hat, in denen der Mensch für den Hund unsichtbar, unerahnbar geworden ist.”) (BROD. Verzweiflung und Erlösung im Werk Franz Kafkas, p. 9) arriscaram-se em interpretações para as chamadas "Tiergeschichte”. Günter Anders, em 1951, e Adorno, dois anos depois, também refletiram sobre o assunto; Gilles Deleuze e Félix Guattari construíram a partir deste e outros aspectos uma sólida proposta teórica em Kafka, por uma literatura menor (1975). Ultimamente, os estudiosos Margot Norris, em 1983, Chris Danta e Matthew T. Powell, em 2008, Marc Lucht e Donna Yarri, em 2010, refletiram sobre o assunto, sem esquecermos o filósofo italiano Giorgio Agamben, para cujas ponderações Kafka é fundamental. No Brasil, recentemente, Susana Kampff Lages, Jeanne Marie Gagnebin e Márcio Seligmann-Silva tocaram no mesmo tema. Os estudos mencionados (com exceção de Agamben, que trabalha muito difusamente com a produção kafkiana) se encontram nas Referências, ao fim destas reflexões. 
Odradek, as sereias, um cruzamento de cordeiro e gato, um inseto não identificado, anjos, as bolinhas azuis do solteirão Blumfeld). ${ }^{8}$ Um verdadeiro jardim zoológico, admitamos.

A frequência da palavra Tier e derivados, na obra de Kafka, é tão consistente que inviabiliza uma interpretação singular de suas figuras da animalidade. Formula-se a expressão dessa maneira porque efetivamente não é o caso de nos limitarmos à nomeação dos animais propriamente ditos; há mais, como as metáforas, as figuras de linguagem, o uso de verbos característicos (fressen, saufen, kriecheln, verkriechen, reiten), a criação de um ambiente evocativamente inóspito e agreste, como o de Der Kübelreiter ( $O$ cavaleiro do balde) etc. Exemplo de um uso peculiar do substantivo é o apelido que o escritor dava à própria tuberculose de que veio a morrer, Das Tier, ${ }^{9}$ que significa “o animal”.

Embora seja tentador aproximar esse gesto ao de, por exemplo, Henry James, que, em 1903, descreve o estado de ansiedade frente ao desconhecido e o senso de urgência e catástrofe como uma fera na selva que, num autêntico réculer pour mieux sauter, prepara-se para atacar, ${ }^{10}$ o léxico do autor de língua alemã se refere a algo simultaneamente mais geral e mais neutro: Tier, que pode ser traduzido simplesmente por “animal”, está distante da ideia de uma besta de carga, um animal fantástico ou fera selvagem, vocábulos que serão obtidos com formas compostas, tais como Lasttier (“animal de carga”), Untier (“monstro”)" ${ }^{11}$ e Raubtier (“predador”), ou distintas, como Biest e Bestie (“fera”, “besta”).

Kafka não dramatiza a enfermidade em algo necessariamente nocivo, violento ou agressivo, mas antes potencialmente doméstico, familiar. Por outro lado, é de se supor que, por detrás da aparente simplicidade, se esconda não apenas a noção de que a doença é uma alteração de ordem biológica dentro de um sistema (quais as borboletas brancas de $O$ mundo animal e outros $\operatorname{contos}^{12}$ ), como também a do abismo intransponível entre a compreensão de

${ }^{8}$ Conquanto pareça exaustiva, a lista é sumária. Para algo mais completo, se bem que partindo-se das edições em inglês, cf. YARRI. Index to Kafka’s use of creatures in his writings, p. 269-283.

${ }^{9}$ HESELHAUS citado por SOKEL. Kafka’s “metamorphosis”: rebellion and punishment, p. 207.

10 "Something or other lay in wait for him, amid the twists and the turns of the months and the years, like a crouching Beast in the Jungle. It signified little whether the crouching Beast were destined to slay him or to be slain. The definite point was the inevitable spring of the creature (...)”. (JAMES. The beast in the jungle, p. 22.)

${ }^{11}$ Significativo uso da palavra se encontra na Metamorfose: “'Liebe Eltern', sagte die Schwester und schlug zur Einleitung mit der Hand auf den Tisch, 'so geht es nicht weiter. Wenn ihr das vielleicht nicht einsehet, ich sehe es ein. Ich will vor diesem Untier nicht den Namen meines Bruders aussprechen, und sage daher bloß: wir müssen versuchen, es loszuwerden. Wir haben das Menschenmögliche versucht, es zu pflegen und zu dulden, ich glaube, es kann uns niemand den geringsten Vorwurf machen'.” (KAFKA. Das Werk, p. 1.139.)

${ }^{12}$ Di BENEDETTO. Borboletas de Koch, p. 15-17. 
um fato e o seu real significado; no caso, patenteia-se, no nosso próprio corpo, insanável desentendimento, como se dá entre o homem e os demais animais, que manifesta o quanto a própria imprevisibilidade e o desconhecimento de si nos definem, posto que angustiem.

Examinando outros usos da animalidade em Kafka, há efetivamente uma variedade assustadora. Nos diários de viagem, o escritor, vegetariano convicto e cavaleiro contumaz, compara, em 18 de janeiro de 1915, suas narrativas a cavalos: “... comecei uma nova história, as antigas temi corromper. Agora estão diante de mim quatro ou cinco histórias erguidas como os cavalos diante do diretor de circo Schumann no começo da produção.”13”,

Essa riqueza comprova que a presença dos animais em Kafka, sendo vasta e abrangendo tanto os textos autobiográficos como a escrita literária propriamente dita, não pode ser reduzida a uma fórmula, por mais elaborada que seja. Assim, embora Deleuze e Guattari tenham analisado extensivamente esse aspecto da obra kafkiana, e diversos autores tenham optado por considerar as histórias de animais ${ }^{14}$ alegorias, ao passo que outros as têm por elaborações inseparáveis de dados históricos e socioculturais e outros, ainda, por símbolos, a diversidade segue sendo difícil de abarcar. ${ }^{15}$ Contudo, se não há explicação única, abre-se a possibilidade de haver ao menos duas explanações, conforme Hadea Nell Kriesberg: “O que é impressionante nos animais de Kafka é que eles têm um papel duplo, aparentando falar tanto como a voz interior de Kafka no momento em que ele medita sobre sua vida como personagens por direito próprio.”16

13 “Trotzdem eine neue Geschichte angefangen, die alten fürchtete ich mich zu verderben. Nun stehen vor mir 4 oder 5 Geschichten aufgerichtet wie die Pferde vor dem Cirkusdirektor Schumann bei Beginn der Produktion.” (Texto original alemão disponível em: $<$ http://gutenberg.spiegel.de/buch/162/8>.)

${ }^{14}$ Considerando apenas aquelas em que animais não humanos são protagonistas, temos, por exemplo: Investigações de um cão (Forschungen eines Hundes), Pequena fábula (Kleine Fabel), Um relatório para uma academia (Eine Bericht für eine Akademie), Josefina, a cantora ou o povo dos ratos (Josefine, die Sängerin oder das Volk der Mäuse), A construção (Der Bau).

15 "Ler Kafka é cruzar constantemente dois desertos, o da literalidade e o da simbolização, em busca desesperada por água. O que acontece é que desprevenido e cansado pela desidratação, o leitor não pode perceber que o que divide os dois desertos é um rio que flui direto do trono de Deus. Em outras palavras, o narrador kafkiano é o tosco costureiro do véu que cobre Seu rosto - já que ninguém pode, sem sucumbir, vislumbrá-lo -, e que, por rebarbas e aberturas mal costuradas permitem ao tímido leitor auspícios aproximados, sem ver exatamente apenas véu ou apenas rosto. Este véu é sua imagem metafórica.” (AMORIM. Considerações sobre imagem e gesto na obra de Franz Kafka, p. 40.)

16 "What is striking about Kafka's animals is that they have a dual role, seeming to speak both as Kafka's inner voice as he meditates on his life and as characters in their own right. (...) Just as the Hassidic parables exist in a particular kind of universal timelessness, an abstract place of time and space, Kafka's stories seem both abstract and literal, a physical meeting ground for human and 
O sobrenome, segundo afirmam os estudiosos, vem do tcheco kavka, "corvo" ou “gralha”. ${ }^{17}$ Biólogos e poetas podem objetar que essas duas espécies são consideravelmente diferentes. Mas a confusão, instaurada desde logo, não é de forma alguma inocente. Sem adentrar a produção literária stricto sensu de Kafka, ainda no domínio das denominações, vemos que também Anschel, o nome judeu do advogado e do seu bisavô materno (conforme lemos na entrada de 25 de dezembro de 1911 nos Diários), introduz outra variante, pela parecença com a palavra alemã Amsel ("melro”). A pouca familiaridade que a evocação da ave europeia talvez desperte pode-se diluir com o recurso a outra língua: o melro atende, em inglês, pela alcunha de blackbird. ${ }^{18}$

Essas considerações aparentemente periféricas não se pretendem arbitrárias; querem, antes, dividir com o leitor a convicção de que a tarefa de estudar Kafka não pode ser expressa com uma fórmula melhor do que a do aforismo escrito em 1917 nos cadernos in-octavo que adotamos como ponto de partida: a gaiola que abre os braços para fisgar um pássaro que, ao contrário de nós, pode voar, e nos deixará, quando assim o quiser, de mãos vazias. Eis a perplexidade que um colecionador de truz expressará, ao se perguntar: “conhecemos a doutrina contida nas parábolas de Kafka e que é ensinada nos gestos e atitudes de $\mathrm{K}$ e dos animais kafkianos?”19

Que o autor da Carta ao pai retoma a tradição da fábula, refundida sem o compromisso de, na experiência de crise generalizada - o tom apocalíptico e carregado dos expressionistas em suas manifestações mais histéricas não é próprio de Kafka, mas nele se

nonhuman animals.” (KRIESBERG. "Czechs, Jews and dogs not allowed”: identity, boundary, and moral stance in Kafka’s “a crossbreed” and "jackals and Arabs”, p. 34.)

${ }^{17}$ Sobre a onomástica de Kafka e as camuflagens do próprio autor no nome de suas personagens (Raban, Rabensteiner, Gracchus, K etc.), consultar o capítulo “As alusões” de ROBERT. Franz Kafka, p. 104-129; HUGUES. Kafka research 1974-1979: a report, p. 163-183; MAURER. Trends in literary scholarship German literary onomastics: an overview, p. 89-105; e ROBIN. Kafka et l'hétérogène, p. 46.

${ }^{18}$ Este foi, ademais, o sobrenome do poeta romeno de língua alemã Paul Celan, que adotou como pseudônimo a inversão das sílabas do nome de família Antschel e consolidou, assim, a aproximação com Kafka pela apropriação de uma relação de parentesco (cf. LISKA. When Kafka says we: uncommon communities in German-Jewish literature, p. 174) Outras formas possíveis seriam: Asher (hebraico), Ascher, Amsel (alemão), Amschel, Anschel (iídiche), Ancsel, modificados de acordo com a necessidade do povo judeu de, seja por imposição, seja como medida de autoproteção, adaptar-se em terras estrangeiras. O mais usual era adotar denominações que tivessem grafia e ou sonoridade semelhante à do nome civil ou pelo menos à da língua falada na região (essas informações foram colhidas em KOMOROCZY et al. Jewish names in Jewish Budapest: monuments, rites, history, p. 190.) Entre os judeus, o uso do nome ritual ficaria restrito ao serviço na sinagoga, prática que, no caso de Kafka, já se tornara rara.

${ }^{19}$ BENJAMIN. Franz Kafka: a propósito do décimo aniversário de sua morte, p. 148. 
acham as tintas carregadas da desesperança e da negatividade -, propor certezas e determinações morais, é quase consenso entre a crítica. ${ }^{20}$ Acontecimento deveras incomum, visto que "é de fato característico de todas as histórias de Kafka que elas evoquem dentro do leitor uma perturbadora multiplicidade de associações e linhas de pensamento”. ${ }^{21}$

A catalogação é mais problemática do que aparenta. ${ }^{22}$ Nem Kafka, nem cada uma de suas narrativas, nem a obra, tomada como conjunto, nem as personagens que ele plasmou, nem as formas, origens ou intenções por detrás do seu pensamento são classificáveis. E, parece-nos, conseguir encaixá-lo numa gaveta tampouco nos faria dominar seus segredos (se destruir um brinquedo para ver o que há dentro dele já não satisfaz, imaginem destruir ou tentar reduzir um ser vivo, incomensuravelmente frágil).

Num Bestiário humano, talvez Odradek tivesse lugar, e um bom desenhista não encontraria maiores dificuldades para ilustrá-lo, utilizando para tanto os dados apresentados. Porém, classificar Odradek não auxilia em nada o entendimento desse texto. Que ele [a criatura] tem a ver com os homens, é algo já dado. Esse esforço de classificar, na verdade, já é um aspecto de nossa identificação com o pai de família. ${ }^{23}$

A instabilidade e a indecidibilidade que encontramos em Kafka nos permite experimentar, ainda que momentaneamente, a sensação da vacuidade do conhecimento e da lógica humana. Eis, com efeito, Graco (do italiano gracchio [?]), encontrado no espólio do escritor numa narrativa permeada da presença animal; o Caçador não pode deixar de tratar com descaso complacente o prefeito da cidade, que tenta descobrir o estatuto do morto-vivo e perscrutar suas intenções e desígnios. A ironia do nome do político, Salvatore, e a impotência dessa autoridade nos mostram que habitamos não um mundo de limites bem definidos, mas um estranho e desconfortável espaço de trânsito ${ }^{24}$ ao qual chegamos não se sabe como, apenas quando; e do qual sairemos não se sabe quando nem como.

${ }^{20}$ Por exemplo, STINE. Franz Kafka and animals; POWELL. Bestial representations of otherness: Kafka's animal stories; e MÜLLER. Consolation in your neighbor's fur: on Kafka's animal parables. Para dados completos relativos a esses artigos, cf. Referências.

21 "It is indeed characteristic of all Kafka's stories that they evoke within the reader a confusing multiplicity of associations and trains of thought.” (FOULKES. Kafka’s cage image, p. 471.)

22 "There are difficulties inherent in the task of cataloging creatures in Kafka's writings." (YARRI. Index to Kafka's use of creatures in his writings, p. 270.)

${ }^{23}$ MANDELBAUM. Franz Kafka: um judaísmo na ponte do impossível, p. 28.

${ }^{24}$ Para Mandelbaum, a ânsia de deslocamento “materializa o profundo empenho” das personagens kafkianas e aproxima as narrativas do escritor do gênero épico. (MANDELBAUM. Franz Kafka: um judaísmo na ponte do impossível, p. 107.) 
A experiência do limiar, da passagem, da transição, as metáforas das portas, dos corredores, dos vestíbulos, tudo isso povoa a obra de Kafka - mas não leva a lugar nenhum. Pior: o limiar parece ter adquirido uma tal espessura que dele não se consegue sair, o que acaba negando sua função. Tenta-se atravessar uma porta escancarada sem poder sair do lugar, como se encena na parábola central de $O$ processo, "Diante da Lei”. Assim, vagamos na obra de Kafka de limiar em limiar, de corredor em corredor, de sala de espera em sala de espera, sem nunca chegar aonde se almejava ir e correndo o risco de esquecer o alvo desejado. ${ }^{25}$

Argumentando, ainda, a partir de apenas um dos escolhos que se nos apresentam, a presença das criaturas não humanas em Kafka não pode ser rotulada tão somente como simbólica, metafórica ou alegórica. Defendendo que o recurso criativo a expressões idiomáticas e provérbios é levado às últimas consequências em A metamorfose (Die Verwandlung), ${ }^{26}$ Walter Sokel se apressa a acrescentar que apontar a novela em questão como uma única metáfora ampliada seria equivocado: para o estudioso, “[r]eside na natureza da profundamente ambígua arte de Kafka que nenhuma análise isolada possa abranger completamente sua multifacetada criação.”27

[E]ssa qualidade leva Deleuze e Guattari a defender que as histórias de Kafka "são essencialmente animalísticas, mesmo quando não há animais nas histórias. Assim, o termo devir animal contém tanto as histórias com animais como aquelas sem eles. Ao chamá-las animalísticas ao invés de animais, Deleuze e Guattari focam na animalidade do humano nas histórias (mais que no animal). Tanto para Adorno quanto para Deleuze e Guattari, as parábolas animais de Kafka articulam o momento em que humanos são e não são eles mesmos, quando eles experienciam aquela parte deles mesmos que é animal. $^{28}$

${ }^{25}$ GAGNEBIN. Entre a vida e a morte, p. 19.

26 'In German usage the appellation 'dreckiger Käfer' ('dirty bug’) denotes a slovenly and unclean individual. Kafka transforms the metaphor into a narrative with a minutely detailed bourgeois setting. (...) [T] he charwoman in the story calls Gregor an "alter Mistkäfer.” Mistkäfer literally means any species of beetle whose habitat is dung, garbage, and dirt generally.' Figuratively the term denotes, in Austrian and South German usage, a person of unclean and untidy habits. Gregor's father, before he can know of Gregor's metamorphosis, assumes that Gregor's room is untidy. He assures his son that the chief clerk will excuse the disorder in his room - a disorder expected of someone whom one would call 'alter Mistkäfer.' Gregor's metamorphosis into a disgusting insect seems to confirm the father's opinion of his son." (SOKEL. Kafka's "metamorphosis”: rebellion and punishment, p. 203-204.)

27 "It lies in the nature of Kafka's deeply ambiguous art that no single analysis can completely comprehend his multi-faceted creation." (SOKEL. Kafka's "metamorphosis": rebellion and punishment, p. 205.)

28 "In fact, this quality leads Deleuze and Guattari to argue that Kafka's stories 'are essentially animalistic even though there aren't animals in all the stories.' Thus, the term becoming animal encompasses both the stories with animals in them as well as those without. By calling them animalistic, instead of animal, stories, Deleuze and Guattari focus on the animality of the human in 
“[O] mundo animal é mais do que uma metáfora cômica para as profundezas recurvas e ocultas do próprio Kafka”, ${ }^{29}$ conforme Peter Stine. Daí Christina Gerhardt propor que, "no pensamento de Adorno, os contos de animais de Kafka na verdade falam mais sobre a animalidade de humanos do que de animais.”30 No extremo, isso ocorre no já citado "O cavaleiro do balde”, em que a elipse, figura característica da escrita kafkiana, é tão absoluta que esboça um cavaleiro sem cavalo.

A mesma lógica fica evidente também pela aparição, digamos, fantasmagórica dos seres vivos na forma de comparações, adjetivações e outros recursos literários. É o caso da caracterização do Odisseu de O silêncio das sereias (Das Schweigen der Sirenen), como astuto, “uma raposa tal” (“ein solcher Fuchs”) que enganou a deusa do destino; ou da expressão “manto de pele de raposa” de "Um fratricídio” (Ein Brudermord). Nessa narrativa, que remete ao famoso crime inserido no relato da Criação, ${ }^{31}$ a morte de seres humanos é igualada ao abate de animais, ${ }^{32}$ como também ocorre na execução sacrificial de Josef K. em $O$ processo (Der Proceß). ${ }^{33}$ Contemplemos o fim de Wese, em tradução de Modesto Carone:

- Wese! - grita Schmar, na ponta dos pés, o braço estendido, a faca vivamente abaixada. - Wese! Júlia o espera em vão!

the stories (rather than the animal). For both Adorno and Deleuze and Guattari, Kafka's animal parables articulate the moment when humans are, and are not, themselves, when they are experiencing that part of themselves that is animal." (GERHARDT. The ethics of animals in Adorno and Kafka, p. 168.)

29 "Yet the animal world is more than a droll metaphor for Kafka's own warped and hidden depths." (STINE. Franz Kafka and animals, p. 60.)

30 “But in Adorno's thinking, Kafka's tales of animals actually tell us more about the animality of humans than they do about animals." (GERHARDT. The ethics of animals in Adorno and Kafka, p. 169.)

${ }^{31}$ Gênesis 4, 1-16.

${ }^{32}$ Não se despreze, além disso, a circunstância de que uma pele de animal (o que é assinalado, em alemão, pela palavra Pelz, já que Haut é mais frequentemente empregada em um contexto em que se trata de seres humanos) representa concretamente um ser que já foi morto em um tempo anterior ao presente da narrativa. A violência contra a criatura, portanto, mesmo implícita, não se ausenta.

${ }^{33}$ As últimas palavras de Joseph K. suscitam do narrador a ponderação "era como se a vergonha (Scham) devesse sobreviver a ele" e aqui nos parece interessante propor a proximidade entre as duas narrativas. A sonoridade do nome Schmar, o destruidor de Wese (que evoca o substantivo abstrato Wesen, cujo sentido é ser, criatura, essência), é próxima não só ao termo utilizado no desfecho de $O$ processo, como também ao vocábulo desonra, em alemão, schmach. Todavia, convém uma vez mais recordar a recusa da interpretação fechada e definitiva em Kafka; nada impede que a exclamação “como um cão!” (“wie ein Hund!”) do protagonista se refira ainda à docilidade e à obediência manifestadas por Josef $\mathrm{K}$. De fato, não se trata de alguém que morre como um cordeiro, nos estertores suínos ou com o canto de cisne. Atente-se, de resto, para a presença desta ambiguidade do cão também em Homero (cf. GONÇALVES. Animais, imagens e símbolos nos poetas greco-latinos, p. 15-16.). 
E Schmar golpeia à direita e à esquerda no pescoço e uma terceira vez fundo no ventre. Ratos da água rasgados por uma lâmina emitem um som semelhante ao de Wese. ${ }^{34}$

Em um trecho extenso, todavia elucidativo, Ritchie Robertson observa que, na narrativa que dá nome ao volume Um médico rural e nas outras que integram o livro, a atenção exagerada aos estímulos sensuais e a racionalidade excessiva são tratadas, de resto, como atitudes indiferentemente grotescas que fazem confluir as supostas categorias (e aqui vale notar que Robertson, em um lance que remonta a Jacques Derrida, nos apresenta o homem no singular e os animais no plural):

Kafka constantemente elide os limites entre homem e animais. Em $O$ processo, por exemplo, o cão figura como uma imagem da degradação humana. Josef K. faz os berros do guarda que está sendo chicoteado passarem pelo grito de um cão; ele vê Block degradado a "o cão do advogado"; e, pela justiça poética, morre, ele mesmo, como um cão. Nas histórias em Um médico rural essa metáfora se torna literal. Em um tipo de paródia do Darwinismo, um macaco se torna humano mediante um acelerado processo de evolução, e Bucéfalo, o cavalo de guerra de Alexandre, o Grande, se ajusta a uma não heroica era moderna tornando-se advogado. Em ambos os casos, a transformação é incerta: o macaco Rotpeter não é aceito como um ser humano mas como um macaco que imita seres humanos, e seus desejos sexuais são satisfeitos, à noite, por uma chimpanzé fêmea semiamestrada; enquanto no caso do Dr. Bucéfalo, suas origens eqüinas ainda são discerníveis para o olho treinado do freqüentador de corridas. Outras histórias contêm seres humanos que estão no nível de animais: os nômades que invadem uma cidade que parece chinesa e dormem e comem lado a lado com seus cavalos carnívoros; o moço de estrebaria em "Um médico rural" que emerge de uma pocilga juntamente com dois cavalos a quem ele se dirige como irmão e irmã. Em última instância, a animalidade não é simplesmente negativa. O moço de estrebaria, a quem o médico se dirige como "Seu animal" é possuído por uma brutal sexualidade que o faz atacar Rosa, a empregada do médico; mas o médico, vivendo ao lado dela por anos, mal a notou, e não a tratou como indivíduo. O nome dela aparece pela primeira vez quando o moço de estrebaria o utiliza: antes disso, o médico se refere a ela simplesmente como "a empregada". Aqui temos uma ruptura entre a sensualidade desenfreada do moço de estrebaria e a intelectualidade excessiva do profissional aprisionado em sua estreita rotina. Os lados animal e intelectual da humanidade se separaram. ${ }^{35}$

${ }^{34}$ KAFKA. Um médico rural, p. 54-55. “'Wese!’ schreit Schmar, auf den Fußspitzen stehend, den Arm aufgereckt, das Messer scharf gesenkt, 'Wese! Vergebens wartet Julia!' Und rechts in den Hals und links in den Hals und drittens tief in den Bauch sticht Schmar. Wasserratten, aufgeschlitzt, geben einen ähnlichen Laut von sich wie Wese.” (KAFKA. Das Werk, p. 1.168.)

35 "Kafka constantly elides the boundaries between man and animals. In Der Proceß, for example, the dog figures as an image of human degradation. Josef $\mathrm{K}$. passes off the shrieks of the guard who is being whipped as the cry of a dog; he sees Block degraded into 'der Hund des Advokaten’ (...); and by poetic justice, he himself dies 'wie ein Hund' (like a dog) (...). In the stories in Ein Landarzt this metaphor becomes literal. In the stories in Ein Landarzt this metaphor becomes literal. In a kind of 
Reza o ditado que quanto mais felinos mais murídeos. E, se já seria uma dificuldade traçar parâmetros para analisar apenas as referências estritamente literárias de animais em Kafka (se é que se pode afirmar coisa tal de quem escreveu tanto, em quantidade e qualidade, em diários e cartas), a situação se complica se temos em mente que

ele frequentemente referia-se a si próprio como um animal (de fato, em tcheco a palavra kavka se refere a uma gralha, uma pequena ave eurasiana pertencente ao mesmo gênero do corvo), como quando ele menciona sentirse como "um pardal, praticando seus pulos na escada". Em novembro de 1913 ele se compara a um cão, escrevendo: "no fundo sou uma pessoa incapaz, ignorante, que, se não tivesse sido compelido (...) a ir à escola, não seria habilitado senão para agachar-se no canil, saltar para fora quando a comida fosse oferecida e saltar de volta quando ele a tivesse engolido." Ele também se compara a uma ovelha: "sou realmente como uma ovelha perdida na noite e nas montanhas, ou como uma ovelha que corre atrás dessa ovelha." Em uma obscura entrada da "Noite dos cometas, 17-18 de maio", em 1910, Kafka escreve: "Juntamente com Blei, sua mulher e filhos, de tempos em tempos ouvi a mim mesmo de fora de mim e soou como o choramingar de um jovem gato." 36

O excerto aponta para diversos traços marcantes: a intertextualidade com a parábola da ovelha perdida, uma das numerosas variações em torno do verbo "rastejar" (kriechen,

parody of Darwinism, an ape becomes human through an accelerated process of evolution, and Bucephalus, the war-horse of Alexander the Great, adjusts to an unheroic modern age by becoming a lawyer. In both cases the transformation is uncertain: the ape Rotpeter is not accepted as a human being but as an ape who imitates human beings, and his sensual desires are satisfied at night by a half-trained female chimpanzee; while in the case of Dr. Bucephalus, his equine origins are still discernible to the practiced eye of a frequenter of race courses. Other stories contain human beings who are on the level of animals: the nomads who invade a Chinese-sounding city and sleep and eat alongside their carnivorous horses; the groom in 'Ein Landarzt' who emerges from a pig-style along with two horses whom he addresses as brother and sister. In the latter instance, animality is not simply negative. The groom, whom the doctor addresses as 'Du Vieh' (you brute) (...), is possessed by a brutal sexuality that makes him assault the doctor's maidservant Rosa; but the doctor, living alongside her for years, has barely noticed her, and has not treated her as an individual. Her name first occurs in the story when the groom uses it: before that, the doctor refers to her simply as 'the maidservant.' Here we have a split between the unbridled sensuality of the groom and the overintellectuality of the professional man trapped in his narrow routine. The animal and intellectual sides of humanity have fallen asunder." (ROBERTSON. Kafka as anti-Christian: "Das Urteil," "Die Verwandlung," and the aphorisms, p. 108.)

36 "Often he refers to himself as an animal (indeed, in Czech the word kavka refers to a jackdaw, a small Eurasian bird belonging to the same genus as the raven), as when he mentions feeling like 'a sparrow, practicing [his] jumps on the step.' In November 1913, he compares himself to a dog, writing, 'At bottom I am an incapable, ignorant person who, if he had not been compelled (...) to go to school, would be fit only to crouch in a kennel, to leap out when food is offered him, and to leap back when he has swallowed it." He also compares himself to a sheep: 'I am really like a lost sheep in the night and in the mountains, or like a sheep which is running after this sheep.' In an obscure diary entry from the 'Night of comets, 17-18 May', in 1910, Kafka writes, 'Together with Blei, his wife and child, from time to time listened to myself outside of myself, it sounded like the whimpering of a young cat'.” (LUCHT. Introduction, p. 3-4.) 
hinkriechen, hinschleppen, nachspüren), o homem como um animal entre animais (é o mínimo que podemos deduzir da ideia de uma ovelha em busca de outra, sem esquecer aqui uma possível paródia bíblica: “pode uma ovelha guiar outra ovelha?”), o sofrimento como ponto de contato com a animalidade, o confinamento e/ou aprisionamento (a esse respeito, cumpre notar não só o artigo de Foulkes sobre as imagens de gaiolas na obra de Kafka como o poema “Jaulas”, de Henriqueta Lisboa ${ }^{37}$ ).

Ademais, o criador da ratinha Josefine, embora neto de açougueiro, era vegetariano, aproveitando os queixumes pela dor de dentes de Grete Bloch, uma parceira epistolar a qual seria arriscado descartar como interesse amoroso, para explicitar, em passagem representativa da aversão pelo consumo de carne e do engajamento do escritor, como a prática era abominável:

\begin{abstract}
A gente senta-se à mesa, ri e fala (eu tenho pelo menos a justificativa para mim que nem rio nem falo), e enquanto isso se formam, das minúsculas fibras de carne entre os dentes, germes de podridão e fermentação em quantidade não menor que de um rato morto que está espremido entre duas pedras.

E apenas a carne é assim tão fibrosa, que apenas com grande esforço e mesmo assim não de imediato e completamente possa ser removida, seria necessário então que a gente tivesse dentes de fera, pontiagudos, separados uns dos outros, direcionados para dilacerar as fibras. ${ }^{38}$
\end{abstract}

A carne será, por conseguinte, recorrente indício de nojo e repugnância, o que também aproximará os animais, em sua obra, dos impulsos da libido. Porém, na narrativa "O abutre” (Der Geier), de 1920, publicada postumamente com título de Max Brod, é ainda uma ave a fonte de dor e morte para um moderno Prometeu, que chega a acreditar no autoengano da possibilidade de vencer seu algoz mediante um rifle:

O abutre escutara tranquilamente a conversa, fitando-nos alternadamente. Vi então que ele percebera tudo. Elevou-se com um bater de asas e depois,

37 "De uma para outra jaula./ Com farrapos ou plumas,/cerceando balbucios ou vascas,/é o berço minúscula/jaula.//A cela, a varanda, a casa,/o jardim, a cidade,/com seus itens e suas parlendas,/são enredos - de vime ou ferro/de uma próspera/jaula.// O alto céu/disposto em toldo, tombando/sobre os flancos da terra,/é uma vistosa/jaula./Com seus planetas e suas lunetas/assestadas.//Também o cérebro: de si próprio/arquiteto e/jaula:/cego além dos relâmpagos.” (LISBOA. Jaulas, p. 223-224.)

${ }^{38}$ Carta de 18 de maio de 1914. "Man sitzt bei Tisch, lacht und spricht (ich habe für mich wenigstens die Rechtfertigung, daß ich nicht lache und spreche), und inzwischen entstehen aus winzigen Fleischfasern zwischen den Zähnen Fäulnis- und Gährungskeime in nicht kleinem Mengen als aus einer toten Ratte, die zwischen zwei Steine geklemmt ist. Und nur Fleisch ist derart faserig, daß es nur mit großer Mühe und selbst dann nicht gleich und vollständig entfernt werden kann, es müßte denn sein, daß man Raubtierzähne hat, zugespitzt, auseinandergestellt, zum Zerreißen der Fasern eingerichtet.” (KAFKA; KOCH. Briefe 1914-1917: Kritische Ausgabe, p. 62.) 
empinando-se para tomar impulso, como um lançador de dardo, enfiou-me o bico pela boca até ao mais profundo do meu ser. Ao cair senti, com que alívio, que o abutre se engolfava impiedosamente nos abismos infinitos do meu sangue. ${ }^{39}$

A proximidade de animalidade, doença e morte, estas duas últimas condições que igualam tudo o que vive no destino inescapável, pode ser encontrada, ademais, nos presságios de mal-estar de Gregor Samsa, que culminam na sua transformação em inseto e no conto "Um médico rural.” ${ }^{40}$ Tanto $O$ processo como A metamorfose receberam interpretações - redutoras, é verdade - segundo as quais os sofrimentos dos protagonistas são a metaforização de doenças incuráveis (assim pensam Sokel, no artigo aludido anteriormente, e Zoltan Roman), sem a perspectiva redentora de obras de temática afim (dentro da interpretação da enfermidade como condenação) como A morte de Ivan Ilitch, de Liev Tolstói.

Apoiados em Robertson, Stine e Lucht, tendemos a crer que Kafka não distingue claramente o homem dos demais animais. É, talvez, o que a formulação de Gerhardt exprime, apontando para o fato de que ser animal é ser mortal: "Esboçando a história desta distinção entre homem e animal, Adorno explica, 'ser condenado a um corpo animal era ser fadado à danação’."41 Isso também é o que vemos em "Relatório a uma academia”, quando Rotpeter começa a modificar-se e a adotar os códigos humanos para escapar. O primata problematiza conceitos como a liberdade, mas se mostra atento à encenação que os humanos performatizam para se diferenciarem dos animais e nos transmite a noção de que seu processo não deixa de ser um corrompimento e uma destruição irreversível.

Em “Um velho manuscrito” (“Ein Altes Blatt”), como recorda Ritchie Robertson, bárbaros e cavalos, irmãmente, dividem o alimento com igual voracidade. Nisso também o escritor judeu estava à nossa frente, como afirma Marc Lucht; ${ }^{42}$ as reflexões contemporâneas são capazes de afirmar que

\footnotetext{
${ }^{39}$ KAFKA. O abutre, p. 132. "Der Geier hatte während des Gespräches ruhig zugehört und die Blicke zwischen mir und dem Herrn wandern lassen. Jetzt sah ich, daß er alles verstanden hatte, er flog auf, weit beugte er sich zurück um genug Schwung zu bekommen und stieß dann wie ein Speerwerfer den Schnabel durch meinen Mund tief in mich. Zurückfallend fühlte ich befreit wie er in meinem alle Tiefen füllenden, alle Ufer überfließenden Blut unrettbar ertrank.” (KAFKA. Das Werk, p. 904.)

${ }^{40} \mathrm{O}$ conto dá nome à coletânea Um médico rural (Ein Landarzt), que consta de histórias escritas em torno de 1916-1917 e publicadas em 1919, das quais apenas três, de um total de 14, deixa de citar direta ou indiretamente algum animal.

41 "Outlining the history of this distinction between man and animal, Adorno explains, "To be condemned to an animal body was to be damned'." (GERHARDT. The ethics of animals in Adorno and Kafka, p. 168.)
}

${ }^{42}$ LUCHT. Introduction, p. 9. 
[a] demonstração da convencionalidade ou arbitrariedade da distinção entre homem e animal poderia revelar as escoras morais em jogo na manutenção dessa distinção - nós nos distinguimos ontologicamente dos animais para justificar nosso uso deles como recursos - assim como as conexões entre a dominância humana dos animais e as estruturas de poder patriarcais, aristocráticas, oligárquicas e colonialistas. ${ }^{43}$

As descobertas científicas e a reflexão histórica descortinam uma conclusão (como todas, provisória, mas, não obstante, eficaz): formas do que classificamos de "racionalidade" nem são exclusividade dos seres humanos nem, aliás, são, neles, infalíveis. A crença cega na racionalidade é desconhecimento de si e do outro, medo e covardia:

É a hierarquia, pela qual humanos são considerados superiores à força de sua habilidade para raciocinar, e animais são considerados inferiores por sua inabilidade para raciocinar que também concomitantemente estabelece uma relação diametralmente oposta entre o racional e o irracional, a qual precisa ser reforçada a qualquer custo. A necessidade de suprimir qualquer irracionalidade ou qualquer desejo animal é o que - precisamente devido ao binarismo severo que é impossível manter - ergue sua cabeça e se torna imanejável ou fascista. O medo do irracional, do outro dentro da própria pessoa, é transferido para o outro, onde se procura erradicá-lo pela erradicação do outro. Como Horkheimer e Adorno argumentam na Dialética do Esclarecimento, é a tentativa de apagar a tensão dialética, de agir como se ela tivesse sido suplantada, que tão consequências tão pouco esclarecidas. E é sobre esse aspecto negativo e suprimido da dialética, seja em história natural ou animais, que Adorno se demora, na Dialética Negativa e em qualquer outro lugar. ${ }^{44}$

A expressão do desejo e da sexualidade é outra vertente em que os animais desempenham importante papel na obra de Kafka, mas sem que medo e crueldade sejam excluídos. Nos exemplos abaixo, extraídos de O processo, "Um relato para uma academia”

43 "The demonstration of the conventionality or arbitrariness of the distinction between human and animal would reveal the moral stakes at play in the maintenance of that distinction - we distinguish ourselves from animals ontologically in order to justify our use of them as resources as well as the connections between the human dominance of animals and patriarchal, aristocratic, oligarchic, and colonialist power structures.” (LUCHT. Introduction, p. 7.)

44 "It is the hierarchy, by which humans are deemed superior by dint of their ability to reason, and animals are deemed inferior because of their inability to reason, that also concomitantly sets up a diametrically opposed relationship between the rational and the irrational, one that must be enforced at all costs. The need to suppress any irrationality or any animal desires is what - precisely because of the stringent binary that is impossible to maintain - rears its head and becomes unmanageable or fascistic. The fear of the irrational, of the other within oneself, became transferred to the other, where one sought to eradicate it by eradication of the other. As Horkheimer and Adorno argue in Dialectic of Enlightenment, it is the attempt to erase the dialectical tension, to act as though it had been superseded, that had such unenlightened consequences. And it is this negative and suppressed aspect of the dialectic, be it natural history or animals, over which Adorno lingers in Negative Dialectics and elsewhere.” (GERHARDT. The ethics of animals in Adorno and Kafka, p. 176-177.) 
(Ein Bericht für eine Akademie), A metamorfose e Cartas a Milena (Briefe an Milena), os grifos são nossos:

- Já vou - disse K.; correu para a frente, agarrou-a, beijou-a na boca e depois no rosto inteiro, como um animal sedento que passa a língua sobre a fonte de água finalmente encontrada.

Beijou-a por fim no pescoço, bem na garganta, e deixou os lábios ficarem ali longo tempo. ${ }^{45}$

... porque eu precisava, porque os ouvidos me zumbiam, eu exclamei "alô" em alto e bom tom, esvaí-me num som humano. Com este grito pulei para a comunidade humana e senti o eco "ouçam só, ele fala" como um beijo sobre todo o meu corpo suado. ${ }^{46}$

Após esta confissão, a irmã ficaria tão comovida que romperia a chorar e Gregor treparia então pelo ombro dela para a beijar no pescoço, que, agora que trabalhava, não trazia qualquer gola ou colar. ${ }^{47}$

Quando, porém, estas outras cartas vêm, Milena (...), leio-o, como um animal sedento bebe, e nisso medo e medo, procuro um móvel, sob o qual eu me possa esconder, rezo, tremendo e completamente desacordado no canto, para que tu, como entraste impetuosamente nesta carta, queiras novamente voar pela janela, decerto não posso conservar uma tempestade em meu quarto; deves, em cartas tais, ter a grandiosa cabeça da Medusa, a tal ponto convulsionam-se as serpentes do horror em torno de tua cabeça e da minha as ainda mais selvagens serpentes do medo. ${ }^{48}$

Que fazer diante disso? O que está ao nosso alcance é revelar um pouco da perplexidade que nos assola quando nos vemos compelidos a analisar e classificar essa avis rara.

Por essa razão é que gostaria de trazer um texto pouco conhecido de Kafka encontrado nos cadernos in-octavo e datado de 20 de outubro de 1917. Trata-se de um fragmento que

${ }^{45}$ KAFKA. O processo, p. 43. “ 'Ich komme schon', sagte K., lief vor, faßte sie, küßte sie auf den Mund und dann über das ganze Gesicht, wie ein durstiges Tier mit der Zunge über das endlich gefundene Quellwasser hinjagt. Schließlich küßte er sie auf den Hals, wo die Gurgel ist, und dort ließ er die Lippen lange liegen.” (KAFKA. Das Werk, p. 230.)

${ }^{46}$ KAFKA. Um relato a uma academia, p. 44. Em alemão: "dafür aber, weil ich nicht anders konnte, weil es mich drängte, weil mir die Sinne rauschten, kurz und gut 'Hallo!' ausrief, in Menschenlaut ausbrach, mit diesem Ruf in die Menschengemeinschaft sprang und ihr Echo: 'Hört nur, er spricht!' wie einen Kuß auf meinem ganzen schweißtriefenden Körper fühlte. (KAFKA. Das Werk, p. 1.177.)

${ }^{47}$ KAFKA. A metamorfose, p. 68.

48 "Wenn aber diese andern Briefe kommen Milena (...) lese [ich] es natürlich doch, so wie ein verdurstendes Tier trinkt, dabei Angst und Angst, ich suche ein Möbel, unter dem ich mich verkriechen könnte, ich bete zitternd und ganz besinnungslos in der Ecke, daß Du wie Du in diesem Brief hereingebraust bist wieder aus dem Fenster fliegen möchtest, ich kann doch einen Sturm nicht in meinem Zimmer halten; Du mußt in solchen Briefen den großartigen Kopf der Medusa haben, so zucken die Schlangen des Schreckens um Deinen Kopf und um meinen allerdings noch wilder die Schlangen der Angst.” (KAFKA. Briefe an Milena, p. 59, tradução nossa.) 
consiste somente em um parágrafo, no qual o prosador, mais uma vez, alcança um equilíbrio notável entre o horror e a exuberância da linguagem (que não se esvai na versão caroniana, incluída entre os aforismos sem título ${ }^{49}$ ):

Uma cadela de mau cheiro, que pariu numerosos filhotes, em parte já apodrecendo, mas que na minha infância era tudo para mim, que me segue fielmente o tempo todo, em quem não consigo bater, mas que, mesmo evitando seu hálito, eu me desvio indo para trás e que, se não me decido por alguma coisa, irá me empurrar até o canto já visível da parede, para se decompor totalmente em cima de mim e comigo - é uma honra que me dá? a carne purulenta e cheia de vermes de sua língua em minha mão. ${ }^{50}$

Com o sugestivo título de "Uma vida” (Ein Leben) Kafka fia uma delicada alternância de sentimentos e imagens negativas e positivas. O quadro, que para Ritchie Robertson representaria a visão gnóstica do escritor para a vida como algo repulsivo, pobre e mesquinho, ao qual, não obstante, ele insiste obstinadamente a se apegar, ${ }^{51}$ é, para nós, diferentemente, mais um testemunho do apreço que as criaturas recebem no universo kafkiano. Na contemplação da morte e da vida que coexistem - tão forte e impactante como a descrição da vitalidade dos vermes que se contorcem na ferida do jovem paciente de "Um médico rural" a miséria do agonizante une homem e animal (de fato, se assim não fosse, por que se chamaria a narrativa “Uma vida”?). O que morre, vendo o reflexo vivente, mal percebe a aproximação do fim; porém o que vive, vendo-se refletido naquele que expira, passa ele mesmo pela morte e toma consciência de sua finitude. Não penso haver, aqui, um tornar-se animal, mas, através do espelho, a fusão entre homem e bicho, na solidariedade pelo fim fatal e no aprendizado mais pleno, já que se aprende pela dor e pelo envolvimento afetivo. Mesmo a expressiva sonoridade original, replena dos sons chiados (ch e sch, bem como o s seguido de consoante; $\mathrm{d}$ e t; h aspirado e r) e das rimas internas (em in, end, ei e er) e escassamente moderada pelas vírgulas de uma única oração, sugere o respirar arquejante e entrecortado de um agonizante a quem falta o ar.

${ }^{49}$ KAFKA. Franz Kafka essencial, p. 190. Observe-se que Kafka amiúde mantém variantes em seus escritos.

50 "Eine stinkende Hündin, reichliche Kindergebärerin, stellenweise schon faulend, die aber in meiner Kindheit mir alles war, die in Treue unaufhörlich mir folgt, die ich zu schlagen mich nicht überwinden kann und vor der ich, ihren Athem scheuend, schrittweise rückwärts weiche und die mich doch, wenn ich mich nicht anders entscheide, in den schon sichtbaren Mauerwinkel drängen wird, um dort auf mir und mit mir gänzlich zu verwesen, bis zum Ende - ehrt es mich? - das Eiterund Wurmfleisch ihrer Zunge an meiner Hand.” (KAFKA. Das Werk, p. 653.)

${ }^{51}$ Efetivamente essa avaliação não é estranha ao Kafka dos aforismos. No entanto, considero sempre temerário afirmar peremptoriamente critica ou defende; os posicionamentos políticos, filosóficos, estéticos do autor raramente são explícitos. 
Narrativas míticas sobre crianças expostas no nascimento e socorridas por animais, presente nas culturas greco-romana, quirguiz, mongólica e indiana ${ }^{52}$ denotam que os atributos de compaixão e generosidade não são exclusivos dos seres humanos e, mais do que isso, podem predominar nas outras espécies animais. Paralelamente, a impiedade e a insensibilidade ao padecimento alheio se mostram, nos homens, maximizadas.

Em uma fotografia de 1907, um jovem Kafka discretamente sorridente pousa a mão sobre a cabeça de um cachorro que se encontra levemente desfocado. Outra foto, mais antiga, datada de por volta de 1889-1890, o olhar inteligente do menino parece relaxado; o corpo se apoia sobre um felpudo carneiro de brinquedo; em uma terceira, quando o escritor era ainda um adolescente de aproximadamente 13 anos, o animal parece ausente, mas a assinatura do fotógrafo, a letra, constitui a presença velada: Fuchs, como dissemos, significa raposa. Um filósofo refletira sobre outra imagem do garoto, ressaltando a força do olhar do retratado. ${ }^{53}$ Considerando os entraves burocráticos para reprodução de imagens que não estão em domínio público e o fato de Kafka ter utilizado tão frequentemente este mesmo recurso em suas obras - por exemplo, em Der Verschollene (O desaparecido) e A metamorfose (em cuja capa, acrescente-se, ele insistiu para não fazer figurar ilustração alguma de inseto, mas apenas, quando muito, uma porta entreaberta ${ }^{54}$-, apresentamos aqui tão só descrições, ${ }^{55}$ convidando o leitor a buscá-las para ver-se refletido nos olhos deste peculiar animal, cuja extinção não é certa, mas cujo estudo e investigação, como todos os esforços humanos, não deixará de nos fazer vislumbrar um pouco mais sobre nós mesmos.

Das fábulas aos primeiros livros infantis que, conforme Harriet Ritvo, ${ }^{56}$ abordaram o ensino da História Natural com ênfase no conhecimento dos animais, por inegável que se

52 JILA. Myths and traditional beliefs about the wolf and the Crow in Central Asia: examples from the Turkic Wu-sun and the Mongols, p. 171-72.

${ }^{53}$ BENJAMIN. Pequena história da fotografia, p. 98; BENJAMIN. Franz Kafka: a propósito do décimo aniversário de sua morte, p. 151.

${ }^{54}$ BRADY; HUGUES. Kafka adapted to film, p. 229.

${ }^{55}$ Que o próprio escritor amava as fotografias sugere-o a notável quantidade de imagens suas que possuímos, dos dois anos de idade até pouco antes de sua morte, só ou acompanhado, descontraído ou compenetrado, dentro ou fora de foco, sorrindo, encarando o fotógrafo ou com o pensamento a milhas de distância; corrobora a hipótese que isso ocorra a despeito do custo e da demora do processo, desestimulantes para a maioria dos consumidores. Cumpre notar, de resto, que as novas tecnologias (o cinema, a máquina datilográfica, o telégrafo, o telefone, os meios de transporte etc) sempre exerceram considerável fascínio sobre Kafka, sentimento, é claro, não despido de ambivalência.

${ }^{56}$ RITVO. Learning from animals: natural history for children in the eighteenth and nineteenth centuries. 
tenha a incomunicabilidade entre o homem e os outros animais (incluídos, aqui, os outros animais humanos), os bichos são, para nós, uma forma de autoconhecimento, uma oportunidade de ver-se refletido em seres que, longe de nos devolver o que a vaidade e a presunção desejariam, são fiéis na denúncia de nossa avidez, da crueldade gratuita, do egoísmo não em defesa da sobrevivência e da vida, mas de ilusões que construímos.

As descobertas sobre o que os animais realmente fazem não apenas inspirou estudiosos a tentar entender as vidas mentais de animais não humanos mais adequadamente como também, à medida que a humanidade aprende que não é a única entre tantos a possuir pensamento, forçou-os a começar a repensar o que significa ser humano. ${ }^{57}$

E, utilizando uma confissão que mais uma vez confunde a identidade, retomo Kafka à guisa de encerramento, e não proponho nem soluciono questão alguma.

Sentes tu - o que é o principal - ininterruptas relações entre ti e uma tranquilizadoramente distante, possivelmente infinita altura ou profundeza? Quem o sente sempre, este não deve, como um cão perdido, correr de lá para cá e suplicando, embora mudo, olhar para cá e para lá, este não deve ansiar deslizar para o túmulo, como se ele fosse um saco de dormir cálido e a vida uma fria noite de inverno, este não deve, quando sobe a escada do seu escritório, acreditar ver que ele, ao mesmo tempo, do alto, cintilante em incerta luz, voltando-se na pressa do movimento, balançando a cabeça de impaciência, sai despencando pela escada inteira.

Muitas vezes, querida, penso realmente que estou perdido para o tráfico com as pessoas. ${ }^{58}$

A poesia é, com efeito, um animal indômito que acaba ensinando ao suposto domador que este nada pode com a liberdade da palavra. Buscá-la pode não ter sentido, tal como dedicar-se a uma pequena vida animal que depende de nós. Mas ela sinaliza para a verdade e para algo que não podemos dominar. E só por isso merece nossa atenção.

57 "Discoveries about what animals actually do have not only inspired scholars to attempt to understand the mental lives of nonhuman animals more adequately, but also, as humanity learns that it is not as unique as many have thought, forced them to begin to rethink what it means to be human.” (LUCHT. Introduction, p. 6.)

${ }^{58}$ Carta a Felice Bauer de 7-8 de fevereiro de 1913: "Fühlst Du - was die Hauptsache ist ununterbrochene Beziehungen zwischen Dir und einer beruhigend fernen, womöglich unendlichen Höhe oder Tiefe? Wer das immer fühlt, der muß nicht wie ein verlorener Hund herumlaufen und bittend aber stumm herumschaun, der muß nicht das Verlangen haben, in das Grab zu schlüpfen, als sei es ein warmer Schlafsack und das Leben eine kalte Winternacht, der muß nicht, wenn er die Treppe in sein Bureau hinaufgeht, zu sehen glauben, daß er gleichzeitig von oben, flimmernd im unsichern Licht, sich drehend in der Eile der Bewegung, kopfschüttelnd vor Ungeduld, durch das ganze Treppenhaus hinunterfällt.” (KAFKA. Briefe an Felice, p.110-111.) 


\section{ABSTRACT}

The analysis of the criticism on the presence of animals in Kafka's work suggests that the several occurrences of non-human beings in the author's oeuvre cannot be comprised under a single label, but are endowed with the characteristic mobility and instability of living creatures.

\section{KEYWORDS}

Kafka, animals, theory, poetry

\section{REFERÊNCIAS}

ADORNO, Theodor. Apuntes sobre Kafka. In: . Prismas. Trad. Manuel Sacristán. Barcelona: Ariel, 1962. p. 260-292.

AMORIM, Tomaz Fernandes Izabel. Considerações sobre imagem e gesto na obra de Franz Kafka. Língua, Literatura e Ensino, v. IV, p. 36-42, maio 2009.

ANDERS, Günter. Kafka: pró e contra - os autos do processo. Trad. Modesto Carone. São Paulo: Perspectiva, 1993.

BENJAMIN, Walter. Franz Kafka: a propósito do décimo aniversário de sua morte. In:

Obras escolhidas I. Magia e técnica, arte e política. Trad. Sérgio Paulo Rouanet. São Paulo: Brasiliense, 1994. p. 137-164.

BENJAMIN, Walter. Pequena história da fotografia. In: Obras escolhidas I. Magia e técnica, arte e política. Trad. Sérgio Paulo Rouanet. São Paulo: Brasiliense, 1994. p. 91-107.

BORGES, Jorge Luis; GUERRERO, Margarita. Manual de zoología fantástica. México; Buenos Aires: Fondo de Cultura Económica, 1957.

BRADY, Martin; HUGHES, Helen. Kafka adapted to film. In: PREECE, Julian. (Ed.). The Cambridge companion to Kafka. Cambridge: Cambridge University Press, 2003. p. 226-241.

BROD, Max. Verzweiflung und Erlösung im Werk Franz Kafkas. Frankfurt am Main: S. Fischer Verlag, 1959.

DANTA, Chris. Kafka’s Mousetrap: the fable of the Dying Voice. SubStance, Issue 117, v. 37, n. 3, p. 152-168, 2008.

Di BENEDETTO, Antonio. Borboletas de Koch. In: . Mundo animal e outros contos. Trad. André de Oliveira Lima. Porto Alegre: Globo, 2008. p. 15-17.

DÖBLIN, Alfred. Berlin Alexanderplatz. Trad. Irene Aron. São Paulo: Editora Martins/Martins Fontes, 2009.

FOULKES, A. P. Kafka’s Cage Image. MLN, German issue, v. 82, n. 4, p. 462-471, Oct. 1967.

GAGNEBIN, Jeanne Marie. Entre a vida e a morte. In: OTTE, Georg; SEDLMAYER, Sabrina; CORNELSEN, Elcio (Org.). Limiares e passagens em Walter Benjamin. Belo Horizonte: Editora UFMG, 2010. p. 12-26. 
GERHARDT, Christina. The ethics of animals in Adorno and Kafka. New German Critique, 97, v. 33, n. 1, p. 159-178, Winter 2006.

GONÇALVES, Maria Isabel Rebelo. Animais, imagens e símbolos nos poetas greco-latinos. In: ALARCÃO, Miguel; KRUS, Luís; MIRANDA, Maria Adelaide (Org.). Animalia Presença e representações: Actas do Encontro Animalia. Lisboa: Edições Colibri, 2002. p. $11-31$.

GROSS, Ruth V. Hunting Kafka Out of season: enigmatics in the short fictions. In: ROLLESTON, James (Ed.). A companion to the works of Franz Kafka. Rochester: Camden House, 2002. p. 247-262.

HUGUES, Kenneth. Kafka Research 1974-1979: a report. New German Critique, Special Issue on Modernism, n. 22, p. 163-183, Winter 1981.

JAMES, Henry. The beast in the jungle. London: Penguin Classics, 2011.

JILA, Namu. Myths and Traditional beliefs about the Wolf and the crow in Central Asia: examples from the Turkic Wu-Sun and the Mongols. Asian Folklore Studies, v. 65, n. 2, p. 161-177, 2006.

KAFKA, Franz. A metamorfose. In: Os melhores contos de Kafka. 2. ed. Trad. A. Serra Lopes. Montijo: Arcádia, 1966. p. 15-80.

KAFKA, Franz. Briefe an Felice. Disponível em: <http://www.odaha.com/sites/default/files/ BriefeAnFelice.pdf>. Acesso em: 21 ago. 2011.

KAFKA, Franz. Briefe an Milena. Her. Jürgen Born und Michael Müller. Frankfurt am Main: Fischer Taschenbuch Verlag, 1997.

KAFKA, Franz. Das Werk. Frankfurt am Main: Zweitausendeins, 2008.

KAFKA, Franz. Franz Kafka essencial. Trad. Modesto Carone. São Paulo: Penguin Classics Companhia das Letras, 2011.

KAFKA, Franz. Franz Kafka: Tagebücher 1910-1923. Disponível em: <http://gutenberg.spiegel.de/buch/162/8>. Acesso em 21 de agosto de 2011.

KAFKA, Franz. O abutre. In: __. Os melhores contos de Kafka. 2. ed. Trad. A. Serra Lopes. Montijo: Arcádia, 1966. p. 15-80.

KAFKA, Franz. O processo. Trad. Modesto Carone. São Paulo: Companhia das Letras, 1997.

KAFKA, Franz. Um médico rural. In: Um médico rural. Trad. Modesto Carone. São Paulo: Companhia das Letras, 1999.

KAFKA, Franz. Um relato a uma academia. In: . Nas galerias. Trad. Flávio R. Kothe. São Paulo: Estação Liberdade, 1989. p. 37-45.

KAFKA, Franz; KOCH, Hans-Gerd (Org.). Briefe 1914-1917: Kritische Ausgabe. Frankfurt: Fischer S. Verlag GmbH, 2005.

KOMOROCZY, Geza et al. (Ed.). Jewish names in Jewish Budapest: monuments, rites, history. Trans. Vera Szabó. Budapest/New York: Central European University Press, 1999.

KRIESBERG, Hadea Nell. “Czechs, Jews and Dogs Not Allowed”: identity, boundary, and moral stance in Kafka's "a crossbreed" and "jackals and Arabs". In: LUCHT, Marc; YARRI, Donna. Kafka's creatures: animals, hybrids, and other fantastic Beings. Plymouth: Lexington Books, 2010. p. 33-52. 
KUZNIAR, Alice. A higher language: novalis on communion with animals. The German Quarterly, v. 76, n. 4, p. 426-442, Autumn 2003.

LAGES, Susana Kampff. Posfácio. In: KAFKA, Franz. O desaparecido ou Amerika. Tradução, notas e posfácio se Susana Kampff Lages. São Paulo: 34, 2003. p. 271-292.

LISBOA, Henriqueta. Jaulas. In: Lírica. Rio de Janeiro: J. Olympio, 1958. p. 223.

LISKA, Vivian. When Kafka says we: uncommon communities in German-Jewish literature. Bloomington: Indiana University Press, 2009.

LUCHT, Marc. Introduction. In: LUCHT, Marc; YARRI, Donna (Ed.). Kafka's creatures: animals, hybrids, and other fantastic beings. Plymouth: Lexington, 2010. p. 3-16.

LUCHT, Marc; YARRI, Donna (Ed.). Kafka's creatures: animals, hybrids, and other fantastic beings. Plymouth: Lexington Books, 2010.

MANDELBAUM, Enrique. Franz Kafka: um judaísmo na ponte do impossível. São Paulo: Perspectiva, 2003.

MAURER, Warren R. Trends in literary scholarship German literary onomastics: an overview. The German Quarterly, v. 56, n. 1, p. 89-105, Jan. 1983.

MÜLLER, Burkhard. Consolation in your neighbor's fur: on Kafka's animal parables. In: LUCHT, Marc; YARRI, Donna (Ed.). Kafka's creatures: animals, hybrids, and other fantastic beings. Plymouth: Lexington Books, 2010. p. 101-118.

NORRIS, Margot. Kafka's Josefine: the animal as the negative site of narration. MLN, German Issue, v. 98, n. 3, p. 366-383, Apr. 1983.

POWELL, Matthew T. Bestial representations of otherness: Kafka's animal stories. Journal of Modern Literature, v. 32, n. 1, p. 129-142, Fall 2008

POWELL, Matthew T. Kafka's angel: the distance of god in a post-traditional world. Janus Head, Amherst, v. 11, n. 1, p. 7-23, 2009.

QUINTANA, Mario. A borboleta. Caderno H. In: - Organização, plano de edição, fixação de texto, cronologia e bibliografia de Tania Franco Carvalhal. 2. ed. São Paulo: Globo, 2006. p. 92.

RITVO, Harriet. Learning from animals: natural history for children in the eighteenth and nineteenth centuries. Children's Literature, v. 13, p. 72-93, 1985.

ROBERT, Marthe. Franz Kafka. Trad. José Manuel Simões. Lisboa: Editorial Presença, 1963. ROBERTSON, Ritchie. Kafka as anti-Christian: "Das Urteil," "Die Verwandlung,” and the Aphorisms. In: ROLLESTON, James (Ed.). A companion to the works of Franz Kafka. Rochester: Camden House, 2002. p. 101-122.

ROBIN, Régine. Kafka et l’hétérogène. Études Littéraires, v. 22, n. 2, p. 43-52, 1989.

RUBIÃO, Murilo. O pirotécnico Zacarias. In: Obra completa. São Paulo: Companhia das Letras, 2010. p. 52-59.

SELIGMANN-SILVA, Márcio. Um novo relatório para a academia ou Nós, animais, na obra de Franz Kafka. In: MACIEL, Maria Esther (Org.). Suplemento literário: animais escritos. Belo Horizonte, setembro-outubro/2010, n. 1.332, Secretaria de Estado de Cultura de Minas Gerais.

SOKEL, Walter Herbert. Kafka's “metamorphosis”: rebellion and punishment. Monatshefte, v. 48, n. 4, p. 203-214, Apr.-May 1956. 
STINE, Peter. Franz Kafka and animals. Contemporary Literature, v. 22, n. 1, p. 58-80, Winter 1981.

THEISEN, Bianca. Kafka's circus turns: “Auf der Galerie” and "Erstes Leid”. In: ROLLESTON, James (Ed.). A companion to the works of Franz Kafka. Rochester: Camden House, 2002. p. 171-186.

TSVETÁIEVA, Marina. Ainda ontem, em meus olhos o teu olhar. In: Indícios flutuantes (Poemas). Trad. Aurora Fornoni Bernardini. São Paulo: Martins, 2006. p. 81.

YARRI, Donna. Index to Kafka's use of creatures in his writings. In: LUCHT, Marc; YARRI, Donna (Ed.). Kafka's creatures: animals, hybrids, and other fantastic beings. Plymouth: Lexington Books, 2010. p. 269-283. 